Estuaries, Vol. 19, No. 1, 1996, pp. 75-81.

http://erf.org/journal/

ISSN (electronic): 1559-2758, ISSN (paper): 0160-8347

(C) Estuarine Research Federation. All rights reserved.

\title{
Selective Predation by Blue Crabs on the Gastropod, Bittium varium: Confirmation From Opercula Found in the Sediments
}

\author{
Russell A. Wright ${ }^{1}$, Larry B. Crowder, Thomas H. Martin \\ Department of Zoology, North Carolina State University. \\ ${ }^{1}$ Present address: Aquatic Ecology Laboratory, Department of Zoology, The Ohio State University.
}

\begin{abstract}
Small blue crabs (Callinectes sapidus Rathbun, 43-70 mm carapace width) can influence the sizedistribution of the gastropod, Bittium varium, strongly reducing the contribution of snails $>3 \mathrm{~mm}$ shell length in field enclosures. We test the hypothesis that these size-dependent effects are due to size-selective predation rather than size-dependent emigration from the field enclosures. In laboratory feeding trials, blue crabs showed negative selectivity for snails $<2.5 \mathrm{~mm}$ and positive selectivity for snails $>3.3 \mathrm{~mm}$. When feeding, blue crabs crush Bittium shells, but the opercula are deposited undamaged in the sediment. Sediment from a field enclosure experiment contained 6.5 X more Bittium opercula from enclosures with blue crabs than from enclosures without blue crabs. We reconstructed the size distribution of Bittium killed by blue crabs from the opercula recovered from sediment. This distribution qualitatively matched those "missing" from the size frequency distribution of surviving snails. Estimates of selectivity from laboratory feeding trials predicted the pattern of size-selection from Bittium killed in the enclosures. We also estimated Strauss's linear index of selectivity and Chesson's $\alpha$ based on the size distribution of snails available during the field enclosure experiment. These indices predicted both the pattern of selectivity and the size distribution of Bittium killed in enclosures with blue crabs. We conclude that size-selective predation by blue crabs can explain the observed shifts in Bittium size distributions.
\end{abstract}

\section{Introduction}

Predators can have strong effects on the structure and function of aquatic ecosystems (Paine 1980; Kerfoot and Sih 1987). Predators directly affect the abundance and size-structure of prey populations through removal of selected individuals (Brooks and Dodson 1965; Paine 1976; Virnstein 1977; Summerson and Peterson 1984; Sih et al. 1985; Hines et al. 1990). But, they can also have a variety of indirect effects ranging from modifying food web interactions to altering prey behavior or morphology (Kerfoot and Sih 1987).

Predation effects on benthic prey in marine and freshwater systems have often been studied using mesh enclosures. A major problem with interpreting the outcome of such experiments is the effect of mesh size on prey movements (Cooper et al. 1990). Researchers often face a practical trade-off in selecting mesh sizes large enough to allow relatively uninhibited water flow through enclosures while still retaining the organisms of interest (Cooper et al. 1990). Retaining of organisms is particularly important in predation studies because often the prey most vulnerable to predation also show the strongest behavioral response (e.g., refugeseeking, Sih 1987). Size-dependent prey emigration through relatively large mesh could be misinterpreted as size-selective predation. Alternatively, predator effects might prove difficult to document if the rate of colonization of enclosures by prey exceeds predation rates (Cooper et al. 1990). Few experimental examples allow independent documentation of size-dependent predation mortality relative to prey emigration. We provide such an example in this paper.

Blue crabs (Callinectes sapidus) are very abundant epibenthic predators in southeastern 
United States estuaries. Blue crabs consume a variety of taxa including both infauna and epifauna (Tagatz 1968; Orth 1977; Virnstein 1977, 1979; Nelson 1981; Laughlin 1982; Stanhope et al. 1982), and have previously been shown to deplete prey in field enclosure experiments (Virnstein 1977, 1979; Nelson 1981; Blundon and Kennedy 1982; West and Williams 1986; Martin et al. 1989). A number of studies have shown that blue crabs appear to be size-selective when feeding on mollusks (Juanes 1992); in most studies, crabs and lobsters preferred small-size prey when offered a range of prey sizes. The exceptions to this pattern show either size selection for intermediate-sized prey or no size-selection. None of the examples reviewed by Juanes (1992) showed preferences for large-size prey.

Bittium varium (Gastropoda: Cerithiidae) are seasonally common grazers on algal epiphytes in seagrass and other epibenthic habitats (van Montfrans et al. 1982; Orth and van Montfrans 1984; Thayer et al. 1984; Virnstein and Howard 1987), and may play an important role in estuarine food webs (van Montfrans et al. 1982; Kitting 1984; Heck and Crowder 1991). Grazers such as Bittium may provide a link between primary and secondary production and remove epiphytes that may reduce the productivity and viability of the seagrass host (SandJensen 1977; Orth and van Montfrans 1984; Howard and Short 1986).

In a previous enclosure experiment (Martin et al. 1989), we found blue crabs significantly influenced the distribution and size-structure of the Bittium population. In the presence of blue crabs, Bittium moved up on vertical structures and congregated near the water surface, apparently in an attempt to avoid blue crab predation. Bittium size-frequency distributions were bimodal in the absence of blue crabs; but in enclosures with blue crabs, the upper mode (Bittium $\geq 3 \mathrm{~mm}$ shell length) was significantly reduced (Fig. 5 in Martin et al. 1989). We interpreted this effect as size-selective predation but could not eliminate the alternative hypothesis of sizedependent emigration.

The goal of this study was to evaluate the hypothesis that blue crabs feed size-selectively on Bittium. To evaluate this hypothesis we quantified the size-selectivity of blue crab predation on Bittium in the laboratory, applied these estimates of selectivity to the estimated sizes of Bittium available in an enclosure experiment (Martin et al. 1989) and predicted the size structure of Bittium eaten by blue crabs, and compared the predicted size structure of Bittium eaten by blue crabs with the size-frequency distribution of Bittium killed, as estimated from opercula found in the sediments in our enclosures.

\section{Methods}

POND EXPERIMENT

The pond experiment was conducted over a 1-mo period from mid July to mid August 1985. Twelve round enclosures, each $1 \mathrm{~m}^{2}$ in area, were installed in a small earthen pond (about $500 \mathrm{~m}^{2} ; 1 \mathrm{~m}$ deep) at the Institute of Marine Sciences, University of North Carolina, Morehead City, North Carolina. Unfiltered water from adjoining Bogue Sound was circulated into the pond at about $201 \mathrm{~min}^{-1}$ and drained through a vertical standpipe. The salinity of the pond was about $27 \%$ o throughout the experiment; surface temperatures were about $29^{\circ} \mathrm{C}$. For more details on the physical structure of the pond see Martin et al. (1989).

The walls and bottoms of the enclosures were made of 6-mm-mesh plastic screen. The walls were $1.2 \mathrm{~m}$ high, with a 20 -cm-wide strip of aluminum flashing fixed inside the top of the cylinders to prevent crabs from escaping. The enclosures were filled with about $8 \mathrm{~cm}$ of mud and associated fauna shovelled from the surrounding pond bottom. A $0.1-\mathrm{m}^{2}$ rectangular panel of plastic mesh was hung in the center of each enclosure so that it extended from the surface to the 
bottom. This mesh panel could be removed easily to sample organisms that colonized vertical surfaces (i.e., the walls of the enclosures) .

The original experiment examined the effects of blue crabs and a benthic-feeding fish, spot (Leiostomus xanthurus), on the benthic prey assemblage using a randomized complete block design (Martin et al. 1989); here we refer to the enclosures containing blue crabs only and the control enclosures in which no predators were stocked $(n=3$ for each treatment). Each crab treatment received two juvenile blue crabs (carapace width, point to point, $=43 \pm 2 \mathrm{~mm} \mathrm{SD}$ ). Enclosures were checked daily and crabs that either were injured or had disappeared were immediately replaced with similar size crabs to maintain blue crab densities. Average carapace width of blue crabs at the end of the experiment was $70 \pm 4 \mathrm{~mm}$ SD.

At the end of the experiment, Bittium recovered from the mesh panels were preserved and measured to the nearest $0.1 \mathrm{~mm}$ shell length in the laboratory. A regression relationship was developed from preserved Bittium relating maximum dimension of the operculum to shell length. Using this regression, we could estimate the lengths of snails that had died in the enclosure, leaving their opercula in the sediments. We sampled the benthic organisms present using four 50 -mm-diameter core samples per enclosure. The top $4 \mathrm{~cm}$ of sediment was preserved in $10 \%$ formalin with rose bengal. Bittium opercula retained on $140-\mu \mathrm{m}$ mesh (mesh size chosen based on the minimum possible operculum predicted by the above regression) were counted and measured along their longest axis.

\section{SELECTIVITY EXPERIMENTS}

Six blue crabs (45-60 mm carapace width) were held individually in 20-1 seawater aquaria. We offered them equal numbers of three sizes of Bittium (15 each of small, $<1.5 \mathrm{~mm}$; medium, 1.5-2.5 mm; and large, >3.3. $\mathrm{mm}$ shell length). The crabs were restrained with a dip net while Bittium were added. Blue crabs were observed feeding until about $50 \%$ of the snails were consumed. The crab was then removed from the aquarium. After each feeding bout, we recovered, counted, and measured the remaining Bittium. The number of each size class of Bittium eaten were compared to the expected number had there been selection between sizeclasses using Hotelling's $\mathrm{T}^{2}$, the multivariate analog of a t-test (Roa 1992).

To estimate selectivity for various size-classes from these trials, we calculated Strauss' (1979) linear selectivity index, L, which represents the difference between the relative abundances of a prey item consumed and available in the habitat. Strauss's index takes a value between -1 and +1 , with negative values for selection against, zero for no selection, and positive values for selection for particular size-classes. We also calculated Chesson's $\alpha$ (1978), which takes values between 0 and 1 and can be interpreted as a relative probability of selecting an item per encounter.

\section{ApPlication of SELECTIVITy InDiCES TO POND EXPERIMENT}

We estimated Strauss's (1979) linear index of selectivity for each 0.5-mm shell-length category from the pond experiment. Because growth rates of Bittium in the sizes observed are low $\left(<0.5 \mathrm{~mm} \mathrm{mo}^{-1}\right.$, Fernandez et al. 1988), Bittium sizes in the control treatment at the end of the experiment provide a reasonable estimate of initial sizes available to blue crabs in this shortterm experiment. Final sizes of Bittium available with crabs were estimated from the enclosures. To estimate average sizes of Bittium available during the experiment, we averaged the final sizefrequency distribution without blue crabs (an estimate of initial size structure) and that with blue crabs (an estimate of final size structure). We also assumed that the size frequencies of Bittium 
estimated from the recovered opercula reflected those sizes chosen by blue crabs. Although we report the value of Strauss' index, due to the assumptions made concerning available Bittium, we compared only the sign to that expected from the laboratory selection experiments.

We applied Chesson's $\alpha$ (1978) from our laboratory selection experiments to the distribution of available Bittium sizes from the enclosures (above) to predict the proportion of small, medium, and large snails the blue crabs would eat. These predicted proportions were compared to the observed proportions of these size classes actually consumed (as reflected by opercula in the sediments). We compared proportions of Bittium in different size-classes killed (as represented by opercula found in the sediments) with predicted proportions based on laboratory measures of selectivity by measuring the amount of overlap between the two distributions. We used Percent Similarity (PS $=\Sigma \min \left(\mathrm{p}_{\mathrm{i}}, \mathrm{q}_{\mathrm{i}}\right)$; Krebs 1989) to calculate the overlap.

\section{Results}

Opercula densities averaged $6,661 \mathrm{~m}^{-2}\left(\right.$ range $=2,590-10,608$ opercula $\left.\mathrm{m}^{-2}\right)$ in enclosures with blue crabs; without blue crabs opercula densities were approximately $6.5 \mathrm{X}$ lower (mean $=$ 1,028 opercula $\mathrm{m}^{-2}$, range $=493-1,947$ opercula $\mathrm{m}^{-2}$ ). The relationship between the maximum dimension of Bittium opercula and shell length was well described via linear regression (Fig. 1). The snail size-frequency distribution reconstructed from the limited number of opercula recovered in controls was nearly uniform, but the size-frequency distribution from enclosures with crabs was strongly bimodal (Fig. 2). This pattern is qualitatively similar to the sizefrequency distribution of live Bittium from the enclosures without blue crabs (Fig. 3).

Results from the laboratory feeding trials suggest that blue crabs (45-60 mm carapace width) preferentially choose larger Bittium ( $>3.3 \mathrm{~mm}$, Fig. 4). Large snails were eaten at a significantly higher rate than either medium or small snails $\left(F_{3,3}=31.89, p=0.009\right)$. Blue crabs picked up the Bittium with their maxillipeds and then transferred them to their chelipeds. The snails were held by one pincer, crushed by the other and then placed in the mouth. Opercula fell to the bottom of the aquaria during crushing or were later regurgitated along with other indigestible material. During handling, the blue crabs frequently dropped small Bittium; larger snails seemed to be handled more efficiently. Strauss' (1979) linear index of selectivity, L, was negative for both the small and medium Bittium but was strongly positive for the large Bittium (Table 1). Chesson's $\alpha$ (1978) suggests that blue crabs were about 2X more likely to select medium than small Bittium and 6X more likely to choose large than small Bittium (Table 1).

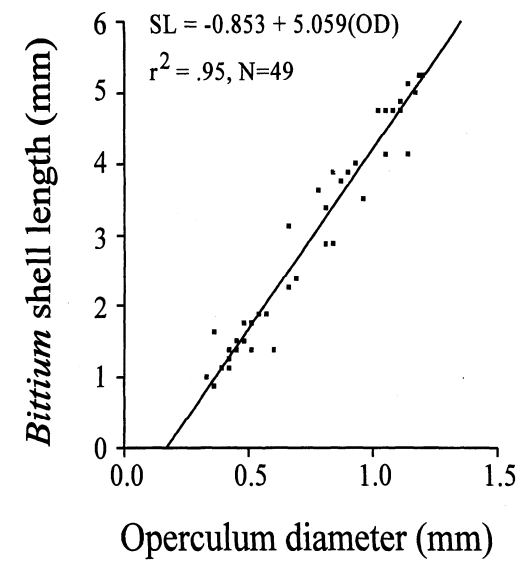

Fig. 1. Regression relationship between operculum maximum dimension and Bittium varium shell length from pond- 
collected animals.

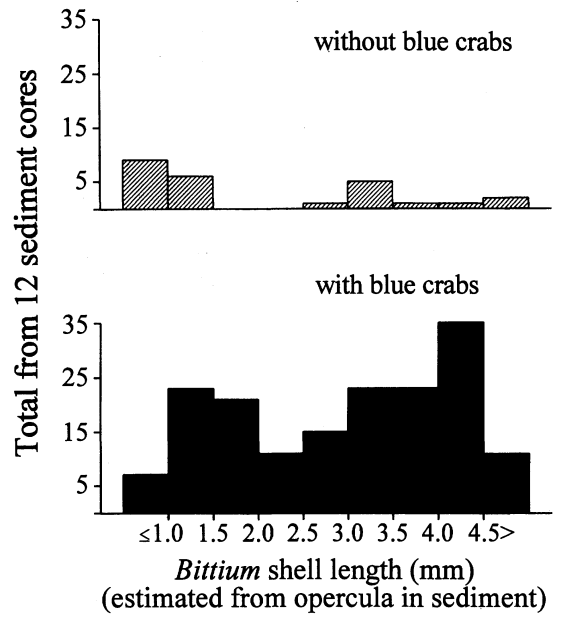

Fig. 2. Length-frequency distributions of Bittium varium determined from opercula recovered in four cores from each of three replicates taken in enclosures containing blue crabs and excluding blue crabs. Shell lengths were estimated from the regression in Fig. 1.

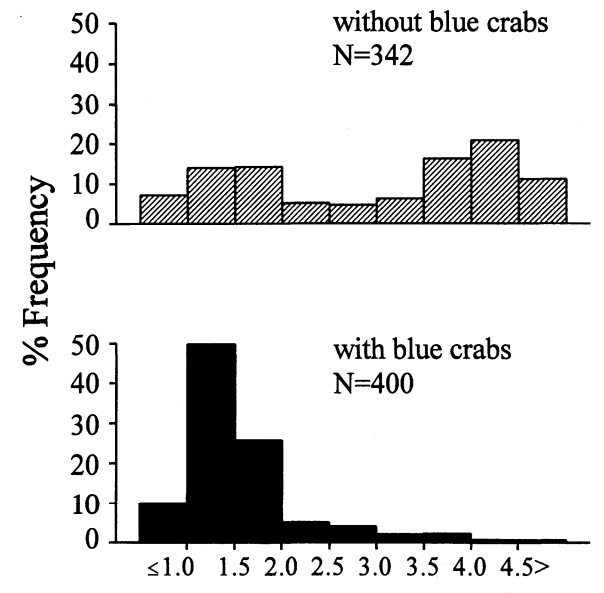

Bittium shell length (mm)

Fig. 3. Bittium varium length distributions in the presence and absence of blue crabs at the conclusion of a 1-mo field enclosure experiment. 


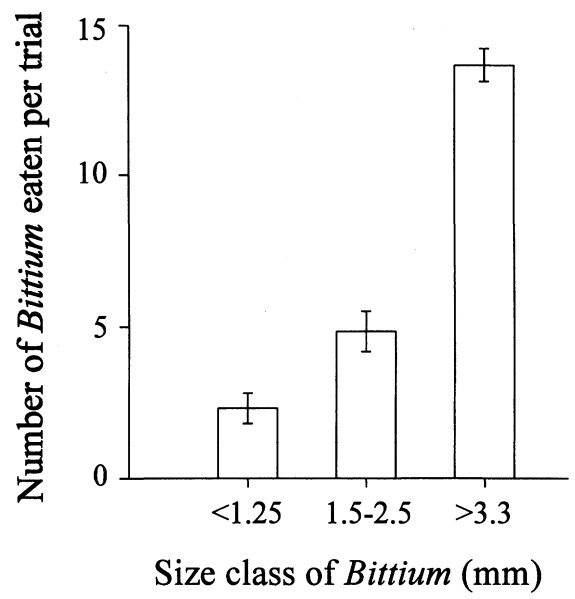

Fig. 4. Mean number of Bittium varium from each of three size classes consumed by blue crabs in laboratory aquaria. Each trial began with 15 snails in each size class. The error bars represent standard errors based on six blue crabs.

TABLE 1. Selectivity of blue crabs on different size-classes of Bittium varium in laboratory aquaria.

\begin{tabular}{lcc}
\hline \multicolumn{1}{c}{ Bittium Size $(\mathrm{mm})$} & Strauss' L & Chesson's $\alpha$ \\
\hline Small $(<1.25)$ & -0.22 & 0.112 \\
Medium $(1.5-2.5)$ & -0.10 & 0.207 \\
Large $(>3.3)$ & +0.33 & 0.680 \\
\hline
\end{tabular}

We compared the estimated size-frequency distribution of Bittium available over the course of the enclosure experiment with the size-frequency distribution of those eaten in enclosures with crabs (based on opercula deposited in the sediments) (Fig. 5). Strauss's index was negative for the three smallest $0.5-\mathrm{mm}$ size classes (i.e., those $<2 \mathrm{~mm}$ ) and was positive for larger Bittium (those $>2 \mathrm{~mm}$ ). This agrees with the laboratory preference trials, which showed negative selectivity for small and medium Bittium $(<2.5 \mathrm{~mm})$ and positive selectivity for larger Bittium.

Bittium available Bittium killed

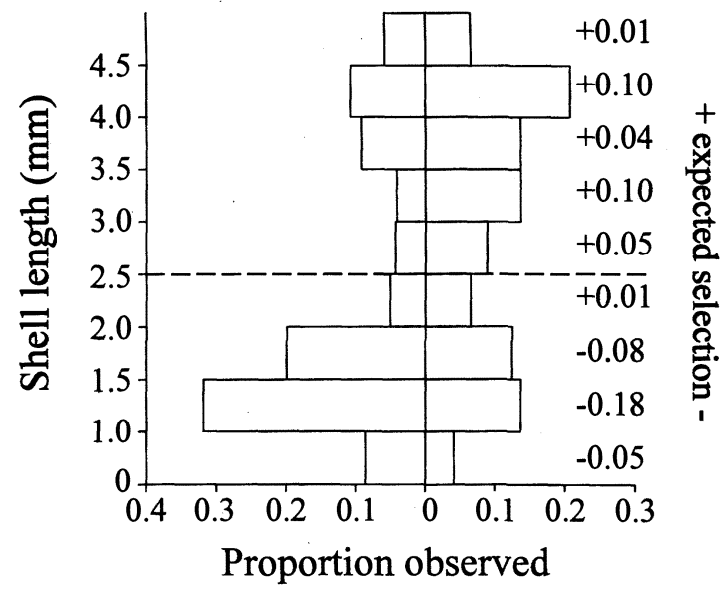


Fig. 5. Average proportion of Bittium varium in various size-classes from enclosures with blue crabs and control enclosures at the end of the experiment. The proportion of size classes killed by blue crabs was calculated from opercula in the sediments of enclosures with blue crabs. The dotted line indicates expected size where selection by blue crabs was negative (based on the laboratory feeding trials, Table 1). Plus and minus signs and numbers next to bars indicate the value of Strauss' L for each size class.

We applied Chesson's $\alpha$ to the size-frequency of Bittium available (as characterized by the average proportion of small, medium, and large Bittium in the enclosures) and estimated the proportions of these size classes that would be eaten by blue crabs (Table 2). The predicted distribution of selected sizes was very similar to that estimated from opercula found in the sediments (Table 2, PS $=89 \%$ ).

TABLE 2. Numbers and proportions of size classes of Bittium killed by blue crabs based on opercula observed in the sediments of the enclosures. These proportions are compared with expected proportions derived from applying Chesson's $\alpha$ from the laboratory experiments (Table 1) to the average size-frequency of Bittium in enclosures with blue crabs and control enclosures from the end of the pond experiment ${ }^{\mathrm{a}}$.

\begin{tabular}{lccc}
\hline Bittium size class $(\mathrm{mm})$ & Number & $\begin{array}{c}\text { Observed } \\
\text { Proportion }\end{array}$ & $\begin{array}{c}\text { Expected } \\
\text { Proportion }\end{array}$ \\
\hline Small $(<1.5)$ & 30 & 0.18 & 0.15 \\
Medium $(1.5-3.0)$ & 47 & 0.28 & 0.20 \\
Large $(>3.0)$ & 92 & 0.54 & 0.66 \\
Total & 169 & 1.00 & 1.01 \\
\hline
\end{tabular}

${ }^{\mathrm{a}}$ Percent similarity $=89 \%$.

\section{Discussion}

In a previous field enclosure experiment (Martin et al. 1989), small blue crabs (43-70 mm carapace width) appeared to have strong size-selective direct-effects on the gastropod, Bittium varium - differentially consuming the larger individuals (those $>3 \mathrm{~mm}$ shell length). But the mesh size we used was relatively large $(6 \mathrm{~mm})$ and could have allowed movement of Bittium into or out of the enclosures. It is possible that the decline in relative abundance of large $(>3 \mathrm{~mm})$ Bittium in the presence of blue crabs was due to size-dependent emigration rather than predation mortality. However, a relatively unique feature of our system was that blue crab effects on the size distribution of live Bittium were mirrored in the opercula deposited in the sediments.

We explored size selectivity by blue crabs on Bittium in laboratory feeding trials and found that blue crabs (45-60 mm carapace width) showed negative selectivity for snails $<2.5 \mathrm{~mm}$ and positive selectivity for snails $>3.3 \mathrm{~mm}$. When feeding on Bittium, blue crabs crush their shells, but many opercula are deposited in the sediment undamaged. The Bittium length distribution determined from opercula essentially account for those missing in the population exposed to crab predation. Estimates of selectivity from feeding trials compared well with the patterns of selection determined from comparisons between the length frequencies of live and dead snails whose sizes were estimated from opercula. Had emigration been the important mechanism altering the length frequency, comparisons between laboratory and field selectivity estimates would have shown relatively far weaker selection for the large Bittium in the field experiment. In this enclosure experiment, it is evident that blue crabs suppressed the abundance of large Bittium via direct predation. Few predation experiments conducted in mesh enclosures can so clearly eliminate prey migration from the size-selective predation as the source of change in prey size frequencies.

Most of the previous literature on size selectivity by decapods on mollusks has focussed 
on relatively large prey species. Juanes (1992) has argued that the selection of smaller prey was a response to mechanical damage of chelae when consuming large, well-protected prey. For small gastropods (Bittium varium, this study, and Littoraria irrorata, Schindler et al. 1994), blue crabs preferentially eat larger individuals. On the large-prey end of the prey spectrum, the ratio of the benefit of eating large prey to the cost of capture and handling may be reduced by costs in the form of damage to chelae. But, on the small-prey end of the diet spectrum, small reward plus diminishing efficiency in handling small prey may prevent the choice of the smallest gastropod prey (Schindler et al. 1994; this study).

Size-selective predation on generalist grazers, such as we have documented here, can lead to changes in biomass, size-structure, and species composition of the prey, potentially altering food-web processes and productivity (Carpenter et al. 1985). The implications of a shift in snail size-structure and behavior on grazing rates is unclear, although grazing rate may scale with body size (Zonneveld and Kooijman 1989). These effects of altering grazer population structure are well documented in freshwater planktonic systems (cf. Carpenter 1988; Carpenter and Kitchell 1993), and may also be important in marine and freshwater benthic and epiphyte- and/or macrophyte-dominated habitats (Orth and van Montfrans 1984; Bell and Westoby 1986a,b; Carpenter and Lodge 1986; Howard and Short 1986; Lodge et al. 1988; Heck and Crowder 1991; Bronmark et al. 1992; Martin et al. 1992). So far, only a few manipulative experiments have examined multiple trophic level effects in marine systems other than rocky intertidal communities (Martin et al. 1989; Kneib 1991; Posey and Hines 1991).

\section{ACKNOWLEDGMENTS}

We thank Carolyn Kindell for laboratory assistance and Libby Marschall and Mark Kershner for commenting on a previous draft of this paper. We acknowledge generous support from University of North Carolina Sea Grant (Projects R/ES-39, R/ES-40, and R/MER-17) and the National Science Foundation (BSR-8709108).

\section{Literature Cited}

Bell, J. D. AND M. Westoby. 1986a. Importance of local changes in leaf height and density to fish and decapods associated with seagrass. Journal of Experimental Marine Biology and Ecology 104:249-274.

BELL, J. D. AND M. WestOBY. 1986b. Abundance of macrofauna in dense seagrass is due to habitat preference, not predation. Oecologia 68:205-209.

Blundon, J. A. And V. S. Kennedy. 1982. Mechanical and behavioral aspects of blue crab, Callinectes sapidus (Rathbun), predation on Chesapeake Bay bivalves. Journal of Experimental Marine Biology and Ecology 65:47-65.

BROOKS, J. L. AND S. I. DodSON. 1965. Predation, body size, and the composition of plankton. Science 150:28-35.

BRÖNMARK, C, S. R KLOSIEWSKI, AND R. A. STEIN. 1992. Indirect effects of predation in a freshwater, benthic food chain. Ecology 73:1662-1674.

CARPEnter, S. R. (ED.). 1988. Complex Interactions in Lake Communities. Springer-Verlag, New York.

CARPenter, S. R. AND J. F. Kitchell (EDS). 1993. The trophic cascade in lakes. Cambridge University Press, Cambridge, Great Britain.

CARpenter, S. R., J. F. Kitchell, And J. R. HodgSOn. 1985. Cascading trophic interactions and lake productivity. BioScience 35:634-639.

CARPenter, S. R. AND D. M. LodGE. 1986. Effects of submersed macrophytes on ecosystem processes. Aquatic Botany 26:341-370.

ChEsson, J. 1978. Measuring preference in selective predation. Ecology 59:211-215.

CoOper, S. D., S. J. WAlde, AND B. L. PeCKARSKY. 1990. Prey exchange rates and the impact of predators on prey populations in streams. Ecology 71:1503-1514.

FERnandeZ, E., R. AnAdOn, And C. FERnANDEZ. 1988. Life histories and growth of the gastropods Bittium 
reticulatum and Barleeia unifasciata inhabiting the seaweed Gelidium latifolium. Journal of Molluscan Studies. 54:119-129.

HECK, K. L., JR. AND L. B. CROWDER. 1991. Habitat structure and predator-prey interactions in vegetated aquatic systems, p. 281-299. In S. Bell, E. McCoy, and H. Mushinsky (eds.), Habitat Complexity: The Physical Arrangement of Objects in Space. Chapman and Hall, New York.

Hines, A. H., A. M. HADDON, AND L. A. WieChERT. 1990. Guild structure and foraging impact of blue crabs and epibenthic fish in a subestuary of Chesapeake Bay. Marine Ecology Progress Series 67:105-126.

HOWARD, R. K. AND F T. SHORT. 1986. Seagrass growth and survivorship under the influence of epiphyte grazers. Aquatic Botany 24:287-302.

JUANES, F. 1992. Why do decapod crustaceans prefer small-sized molluscan prey? Marine Ecology Progress Series. 87:239-249.

Kerfoot, W. C. AND A. SiH. 1987. Predation: Direct and Indirect Impacts on Aquatic Communities. University Press of New England, Hanover, New Hampshire.

KiTTING, C. 1984. Selectivity by dense populations of small invertebrates foraging among seagrass blade surfaces. Estuaries 7:276-288.

KNEIB, R. T. 1991. Indirect effects in experimental studies of marine soft-sediment communities. American Zoologist 31:874-885.

KREBS, C. J. 1989. Ecological Methodology. Harper and Row, New York.

LAUGHLIN, R. A. 1982. Feeding habits of the blue crab, Callinectes sapidus Rathbun, in the Apalachicola Estuary, Florida. Bulletin of Marine Science 32:807-822.

Lodge, D. M., J. W. Barko, D. Strayer, J. M. Melack, G. G. Mittelbach, R. W. howarth, B. MENGE, AND J. E TITUS. 1988. Spatial heterogeneity and habitat interactions in lake communities, $\mathrm{p}$. 181-208. In S. R. Carpenter (ed.), Complex Interactions in Lake Communities. Springer-Verlag, New York.

Martin, T. H., L. B. Crowder, C. F. Dumas, And J. M. Burkholder. 1992. Indirect effects of fish on macrophytes in Bays Mountain Lake: Evidence for a littoral trophic cascade. Oecologia 89:476-481.

Martin, T. H., R. A. Wright, AND L. B. Crowder. 1989. Non-additive impact of blue crabs and spot on their prey assemblages. Ecology 70:1935-1942.

Nelson, W. G. 1981. Experimental studies of decapod and fish predation on seagrass macrobenthos. Marine Ecology Progress Series 5:141-149.

ORTH, R. J. 1977. Effect of nutrient enrichment on growth of the eelgrass Zostera marina in the Chesapeake Bay, Virginia, U.S.A. Marine Biology 44:187-194.

ORTH, R. J. AND J. VAN MONTFRANS. 1984. Epiphyte-seagrass relationships with emphasis on the role of micrograzing: A review. Aquatic Botany 18:43-69.

PAINE, R. T. 1976. Size-limited predation: An observational and experimental approach with the Mytilus-Pisaster interaction. Ecology 57:858-873.

PaINE, R. T. 1980. Food webs, linkage interaction strength, and community infrastructure. Journal of Animal Ecology 49:667-685.

POSEY, M. H. AND A. H. HinES. 1991. Complex predator-prey interactions within an estuarine benthic community. Ecology 72:2155-2169.

ROA, R. 1992. Design and analysis of multiple-choice feeding-preference experiments. Oecologia 89:509-515.

SAND-JENSEN, K. 1977. Effect of epiphytes on eelgrass photosynthesis. Aquatic Botany 3:55-63.

Schindler, D. E., B. M. Johnson, N. A. MacKay, N. Bouwes, And J. F. Kitchell. 1994. Crab:snail sizestructured interactions and salt marsh predation gradients. Oecologia 97:49-61.

SiH, A. 1987. Predators and prey lifestyles: An evolutionary and ecological overview, p. 203-224. In W C. Kerfoot and A. Sih (eds.), Predation: Direct and Indirect Impacts on Aquatic Communities. University Press of New England, Hanover, New Hampshire.

Sih, A., P. H. Crowley, M. A. McPeeK, J. W. Petranka, And K. Strohmeier. 1985. Predation, competition and prey communities: A review of field experiments. Annual Review of Ecology and Systematics 16:269-311.

Stanhope, H. S., W. C. BANTA, AND M. T. TEMKIN. 1982. Size-specific emergence of the marsh snail, Littorina irrorata: Effect of predation by blue crabs in a Virginia salt marsh. Gulf Coast Research Report 7:179-182.

STRAUSS, R. E. 1979. Reliability estimates for Ivlev's electivity index, the foraging ratio, and a proposed linear index of food selection. Transactions of the American Fisheries Society 108:344-352.

Summerson, H. C. AND C. H. Peterson. 1984. Role of predation in organizing benthic communities of a temperate-zone seagrass bed. Marine Ecology Progress Series 15:63-77.

Tagatz, M. E. 1968. Biology of the blue crab, Callinectes sapidus Rathbun, in the St. Johns River, Florida. Fisheries Bulletin 67: 17-33. 
Thayer, G. W., W.J. Kenworthy, And M. S. FonseCA. 1984. The ecology of eelgrass meadows of the Atlantic Coast: A community profile. United States Fish and Wildlife Series. FWS/ OBS-84/02.

VAN MontFrans,J., R. J. ORTH, AND S. A. VAY. 1982. Preliminary studies of grazing by Bittium varium on eelgrass periphyton. Aquatic Botany 14:75-89.

VIRNSTEIN, R. W 1977. The importance of predation by crabs and fishes on benthic infauna in Chesapeake Bay. Ecology 58: 1199-1217.

VIRNSTEIN, R. W. 1979. Predation on estuarine infauna: Response patterns of component species. Estuaries 2:6986.

VIRNSTEIN, R. W. AND R. K. HOWARD. 1987. Motile epifauna of marine macrophytes in the Indian River Lagoon, Florida. I. Comparisons among three species of seagrasses from adjacent beds. Bulletin of Marine Science 41:1-12.

WeSt, D. L. AND A. H. WiLliams. 1986. Predation by Callinectes sapidus (Rathbun) within Spartina alterniflora (Loisel) marshes. Journal of Experimental Marine Biology and Ecology 100:75-95.

ZonNeVELD, C. AND S. A. L. M. KoOIJMAN. 1989. Application of a dynamic energy budget model to Lymnaea stagnalis (L.). Functional Ecology 3:259-278. 